Research Paper: Immunology

\title{
ADAR1 is vital for B cell lineage development in the mouse bone marrow
}

\author{
Victoria Marcu-Malina ${ }^{1}$, Sanja Goldberg ${ }^{1}$, Einav Vax $^{1}$, Ninette Amariglio ${ }^{1,5}$, Itamar \\ Goldstein ${ }^{1,3,4, *}$ and Gideon Rechavi ${ }^{1,2,4, *}$ \\ ${ }^{1}$ Sheba Cancer Research Center, Chaim Sheba Academic Medical Center, Tel Hashomer, Israel \\ ${ }^{2}$ Department of Pediatric Hemato-Oncology, Chaim Sheba Academic Medical Center, Tel Hashomer, Israel \\ ${ }^{3}$ Rheumatic Diseases Unit, Chaim Sheba Academic Medical Center, Tel Hashomer, Israel \\ ${ }^{4}$ Sackler School of Medicine, Tel-Aviv University, Tel-Aviv, Israel \\ ${ }^{5}$ The Mina and Everard Goodman Faculty of Life Sciences, Bar Ilan University, Ramat Gan, Israel \\ * These authors have contributed equally to this work \\ Correspondence to: Gideon Rechavi, email: Gidi.Rechavi@sheba.health.gov.il
}

Itamar Goldstein, email: Itamar.Goldstein@sheba.health.gov.il

Keywords: RNA editing, ADAR1, B cell, lymphopoiesis, epitranscriptomics, Immunology and Microbiology Section, Immune response, Immunity

Received: July 10, 2016

Accepted: July 23, 2016

Published:August 02, 2016

\section{ABSTRACT}

Adenosine deaminase acting on RNA (ADAR) 1 is the master editor of the transcriptome, catalyzing the conversion of adenosine to inosine (A-to-I). RNA transcripts fold into a variety of secondary structures including long intramolecular RNA duplexes that are the major substrate of ADAR1. Most A-to-I editing sites occur within RNA duplexes formed by complementary pairing of inverted retrotransposable elements interspersed within noncoding regions of transcripts. This catalytic activity of ADAR1 most likely prevents the abnormal activation of cytosolic nucleic acid sensors by self-dsRNAs. Homozygous disruption of mouse Adar is embryonic lethal due to a toxic type-I interferons response and correspondingly biallelic missense mutations in human ADAR1 cause a severe congenital interferonopathy. Here, we report that Cd19-Cre-mediated Adar gene ablation in the mouse causes a significant defect in the final stages of $B$ cell development with an almost complete absence of newly formed immature and $\mathrm{CD}_{23}{ }^{+}$mature recirculating $B$ cells in the BM. Adar ablation in pre-B cells induced upregulation of typical interferon-stimulated genes (ISGs) and apoptosis upon further maturation. ADAR1 deficiency also inhibited the in vitro, IL-7-mediated, differentiation of BM-derived B cell precursors. In summary, ADAR1 is required, nonredundantly, for normal $B$ lymphopoiesis in the BM and peripheral maintenance.

\section{INTRODUCTION}

RNA molecules undergo elaborate posttranscriptional modification, such as editing and methylation, collectively termed epitranscriptomics [1-3]. The most prevalent type of RNA editing in mammalians is the deamination of adenosine into inosine (A-to-I editing) primarily catalyzed by ADAR1. The Adar gene encodes a constitutively expressed p110 isoform and a longer interferon-inducible p150 isoform. The two isoforms have different translation initiation sites and promotors. The p110 isoform is present predominantly in the nucleus whereas the interferon-inducible p150 isoform is usually cytoplasmic [4]. The development of bioinformatics methodologies and tools to map A-to-I editing sites revealed that they are highly abundant in untranslated regions (UTRs) of mRNAs $[1,5]$. The majority of editing within UTRs is promiscuous, occurring within long intramolecular RNA duplexes formed by complementary pairing of inverted repeats: e.g., Alu retrotransposons in the human and orthologous short interspersed repetitive elements (SINE) in the mouse $[1,6]$. For example, the human transcriptome contains dense clusters of A-to-I editing sites, termed as hyper-edited, localizing mostly in Alu repeats [7]. 
Genetic ablation of Adar in the mouse is embryonic lethal at midgestation due to defective hematopoiesis and a detrimental type-I interferons response [8-12]. Similarly, infants with mutated $A D A R 1$ develop during early life a severe interferonopathy, the Aicardi-Goutières syndrome (AGS), presenting with encephalopathy and features akin with systemic lupus erythematosus (SLE) and congenital viral infections [13-16]. Recent studies in mouse models show that deletion of genes involved in the innate immune response to double-stranded (ds)RNA rescues ADAR1 deficient mice to birth $[8,17,18]$. Taken as a whole these observations imply that a major biological function of Adar is hyperediting of repetitive elements in the transcriptome to prevent abnormal stimulation of nucleic acid sensing pathways $[19,20]$. ADAR1 has been shown to have other conserved biological functions, as follows: (i) infrequent but important modifications of codons within mature mRNAs [21]; (ii) editing-dependent modifications of the alternative splicing of selected pre-mRNAs [22]; (iii) editing-independent and dependent modulation of microRNA biogenesis and/or function [23, 24].

Despite the fact that ADAR1 is essential for embryonal development, normal fetal and adult hematopoiesis, and maintaining innate immune homeostasis in the mouse and human $[19,20]$, no previous studies have addressed its role in B cell development. In this study, using in vivo Cd19-Cre-mediated conditional ablation of Adar gene, we asked how ADAR1 deficiency affects the late stages of B lymphopoiesis predominantly in the BM.

\section{RESULTS AND DISCUSSION}

\section{CD19-Cre ${ }^{\mathrm{ki}}$-mediated conditional ablation of Adar inhibits B lymphopoiesis}

ADAR1 is required for the early stages of fetal and adult hematopoiesis $[10,25]$. We now asked whether ADAR 1 is also vital for the late phases (from pre-B cell stage and onward) of adult B lymphopoiesis, using a model system of Cd19-Cre ${ }^{\mathrm{ki}}$-mediated recombination of floxed Adar. The B cell lineage develops initially in the BM from common lymphoid progenitors (CLP) through sequential stages: developing from CLP to pre-pro-B cells
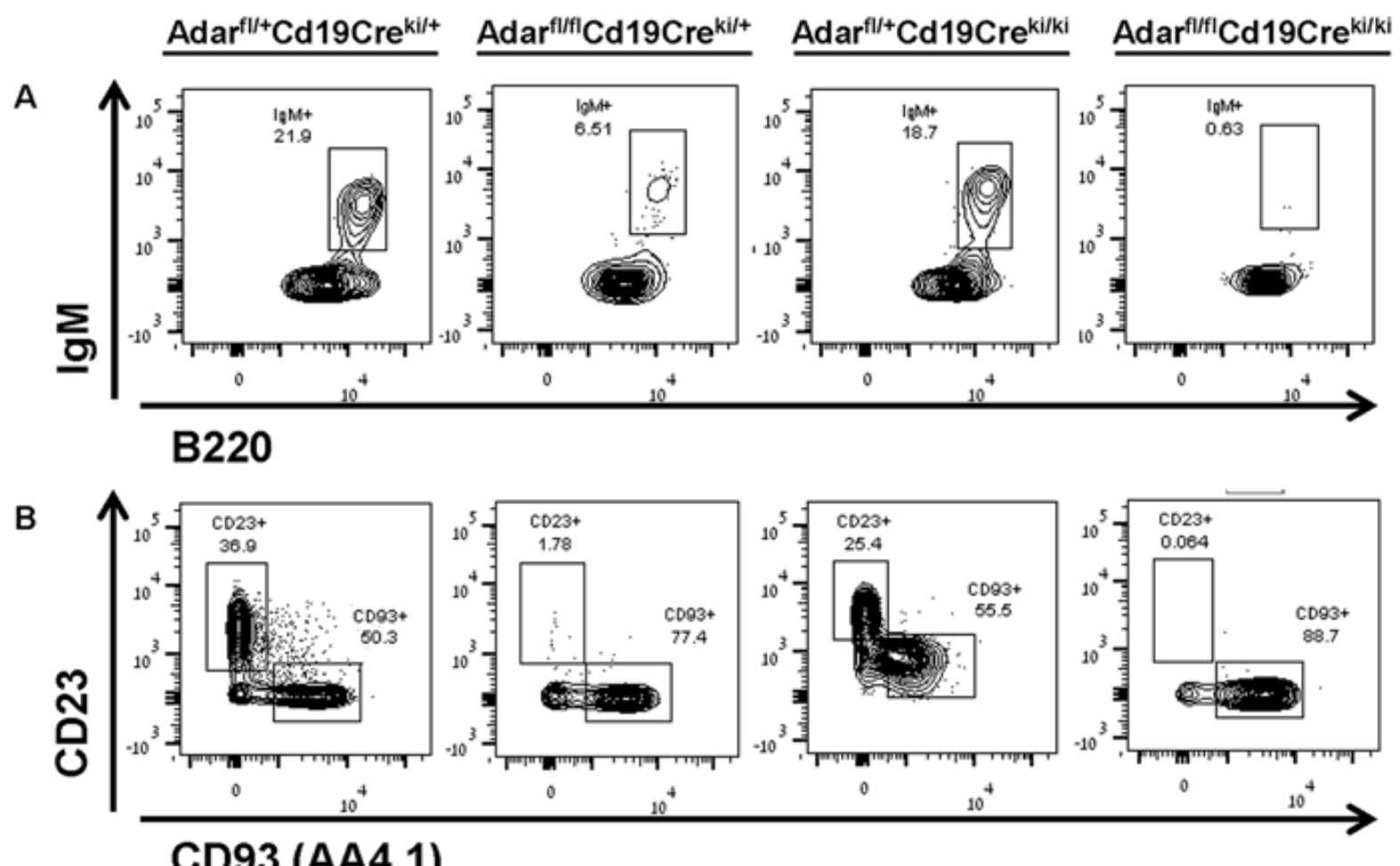

CD93 (AA4.1)

Figure 1: Cd19-Cre-mediated Adar disruption causes profound deficiency of immature and recirculating mature B cells in the BM. Single cell suspension of BM cells were obtained from 8-16 week-old mice and depleted of erythrocytes. Next, to identify B cell precursors in the last stages of B-lymphopoiesis we immunostained the samples with flourochrome-conjugated mAbs as detailed in Materials and Methods. Samples were acquired by a FACSAria instrument and the data ( $>10,000$ events per sample) were analyzed/plotted using the FlowJo V.10 software. A. Upper contour plots depict the percentage of immature $\operatorname{IgM}^{+}$B cells in the indicate group (21.9. 6.51, 18.7 and 0.63, respectively). B. Lower plots show the percentage of MR CD23 ${ }^{+}$D 93- B cells in the indicate group (36.9, $1.78,25.4$, and 0.064 ; respectively) and other less mature B-lineage cells $(50.3,77.4,55.5$, and 88.7 ; respectively). The data shown are from a representative mouse from each of the four indicated genotypes. 
(Hardy classification Fr. A), to pro-B cells (Fr. B/C), to pre-B cells (Fr. D), and lastly to immature/new B cells (Fr. E) [26]. The expression of the CD19 molecule is a marker for B lineage-committed cells, and normally its expression starts at the pro-B cell stage [27]. We selected $\mathrm{B}$ cell-specific expression of Cre from the $\mathrm{Cd} 19$ locus over expression from the $m b l$ gene, as the efficiency of target gene recombination in the first model system is much lower in early precursors $(\mathrm{Fr} . \mathrm{B} / \mathrm{C})$, increasing significantly as the $\mathrm{B}$ cell mature reaching efficiency of $80-95 \%$ in Fr. E to F cells [28]. We used two relevant mouse genotypes $\mathrm{Adar}^{\mathrm{f} / \mathrm{fl}} \mathrm{Cd} 19-\mathrm{Cre}^{\mathrm{ki} / \mathrm{t}}$ and $\mathrm{Adar}^{\mathrm{f} / \mathrm{fl}} \mathrm{Cd} 19^{\mathrm{ki} / \mathrm{ki}}$ to address our question, predicting that the second mutant, homozygous for the Cd19-Cre ${ }^{\mathrm{ki}}$ allele, would display a higher penetrance of biallelic ablation of the floxed Adar gene segment in late B cell precursors.

The FACS analysis of freshly isolated BM cells from Adar ${ }^{\mathrm{f} / \mathrm{fl}} \mathrm{Cd} 19-\mathrm{Cre}^{\mathrm{ki} /+}$ mice for the major stages of $\mathrm{B}$ lymphopoiesis in the $\mathrm{BM}$, revealed a significant reduction of $\sim 70 \%$ in the number of immature B cells (Fr. E) compared to littermate $\mathrm{Adar}^{\mathrm{f} / /+} \mathrm{Cd} 19-\mathrm{Cre}^{\mathrm{ki} /+}$ control mice (Figure 1A and combined data in Figure 2A). In addition, these mutants also showed a very significant reduction of $\sim 75 \%$ in mature recirculating (MR; Fr. F) $\mathrm{CD} 23^{+} \mathrm{CD} 93$ $\mathrm{B}$ cells (Figures 1B and combined data in Figure 2B). As predicted, the $\operatorname{Adar}^{\mathrm{fl} / \mathrm{fl}} \mathrm{Cd} 19-\mathrm{Cre}^{\mathrm{ki} / \mathrm{ki}}$ mice displayed a more profound, less variable, reduction of $\sim 95 \%$ in the percentage of immature B cells compared to littermate controls, and consequently an almost complete lack of MR B cells (Figures 1A-1B, and combined data in Figures 2A-2B). However, these two mutant mice groups did not show a significant reduction in the development and maintenance of more premature B cells precursors, exhibiting normal numbers of Fr. B to D cells in their BMs (data not shown). The percentages of $\mathrm{CD}^{+} \mathrm{T}$ cells and monocytes in their BM were also normal (data not presented).

Newly formed conventional B cells (Fr. E) undergo further maturation in the periphery. Therefore, we also determined the effect of Adar ablation on mature splenic and peripheral blood (PB) circulating $\mathrm{B}$ cells. The combined FACS data showed, yet again, a significant reduction in the percentage of $\mathrm{PB}$ circulating $\mathrm{B}$ cells, total splenic B cells, and transitional T2 plus mature $\mathrm{CD}_{23}{ }^{+}$splenic B cells in the two mutant mice groups compared to respective littermate controls. As expected, the block in B cell peripheral maturation and maintenance was more substantial in $\mathrm{Adar}^{\mathrm{f} / \mathrm{f}} \mathrm{Cd} 19-\mathrm{Cre}^{\mathrm{ki} / \mathrm{ki}}$ compared to Adar ${ }^{\mathrm{f} / \mathrm{fl}} \mathrm{Cd} 19^{\mathrm{ki} /+}$ mutants. The findings that the deleterious biological consequences of $\mathrm{Cd} 19-\mathrm{Cre}^{\mathrm{ki}}$-mediate Adar gene ablation manifested on or after the immature B cell stage (Fr. E to F) agree with our prediction, based on previous data [28], that the penetrance of Cd19-Cre-mediated Adar recombination should become extensive only in the late phases of B lymphopoiesis.

Previous data from the Rajewsky laboratory on the phenotype of homozygous Cd19-Cre ${ }^{\mathrm{ki}}$ mice, lacking surface CD19 expression, show that conventional B cell
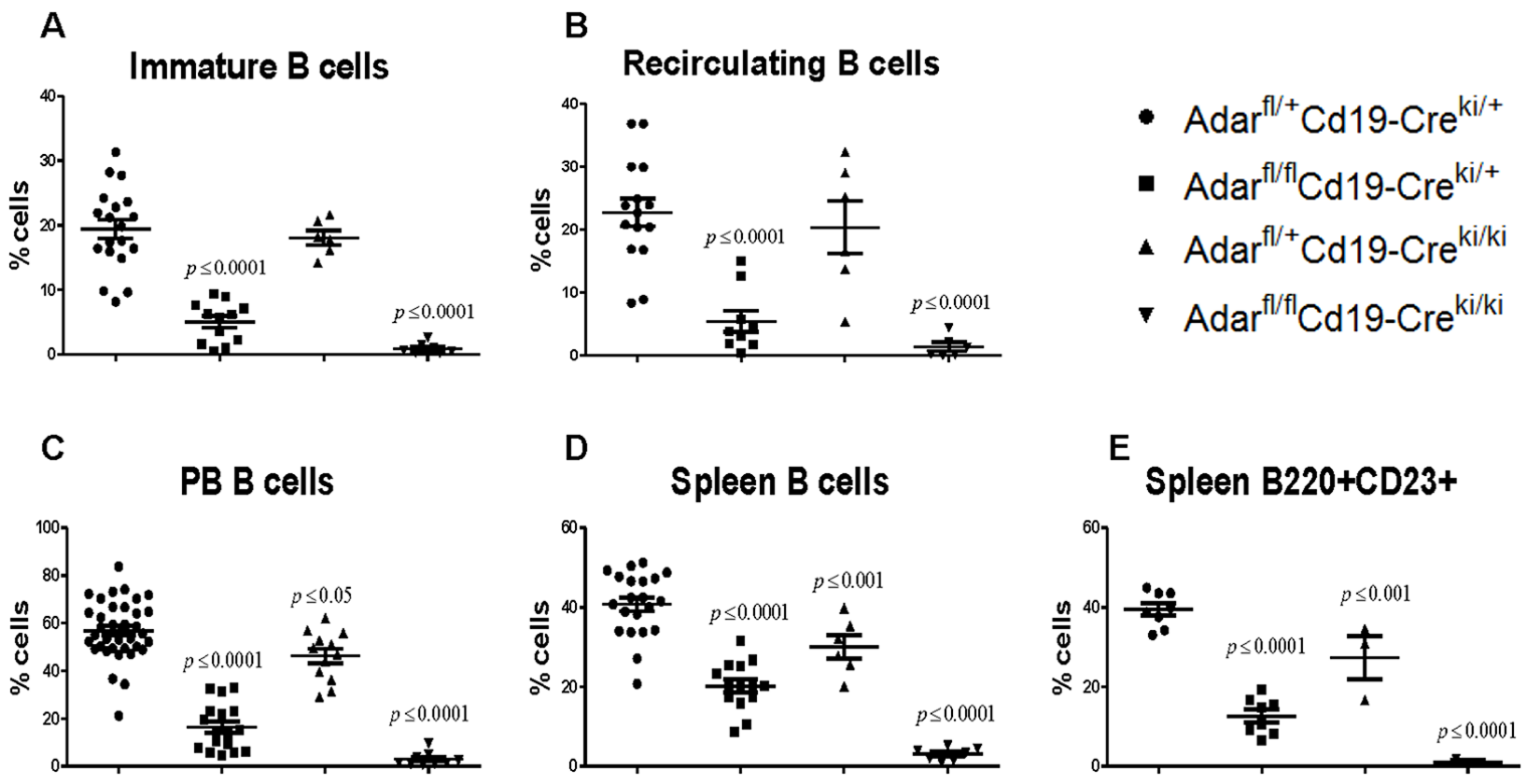

Figure 2: B lineage specific Adar ablation results in a profound deficiency of immature (naïve) and peripheral (mature) $\mathbf{B}$ cell deficiency. Charts show the percentage of $\mathbf{A}$. immature and $\mathbf{B}$. MR B cells in the BMs from a large number of mutants and littermate control mice. C. Percentage of peripheral blood circulating B cells in the four indicated mice groups. Percentage of D. total B220 and E. transitional T2/ follicular CD23 ${ }^{+}$splenic B cells. Each point in the graphs represents the percentage of the specified B cell subset for an individual mouse. Mean values are represented with horizontal bars, and error bars represent \pm SD. $P$ values were determined by the one-way ANOVA test (compared against Adar ${ }^{\mathrm{f} /+} \mathrm{Cd} 19-\mathrm{Cre}^{\mathrm{ki} /+}$ controls). 
development in their BM was undisturbed. However, their peripheral B cells showed a highly reduced capacity to respond to $\mathrm{T}$ cell-dependent antigens and for antibody affinity maturation [27]. Moreover, while CD23+ transitional T2 and follicular splenic B cells were present in adequate numbers in CD19 deficient mice, the subset of innate-like CD23- marginal zone B cells was practically absent [29]. We also found grossly normal percentages of Fr. B to E cells in the BM of Adar ${ }^{\mathrm{fl} /+} \mathrm{Cd} 19-\mathrm{Cre}^{\mathrm{ki} / \mathrm{ki}}$ mice and only a minimal reduction in the percentage of $\mathrm{CD} 23^{+}$ splenic B cells (Figures 1-2 and unpresented data). Taken as a whole these observations lead us to conclude: (i) the deficiency in the late stages of B lymphopoiesis in the two mutants is mostly ADAR1-dependent; and (ii) the more profound maturation block in the $\operatorname{Adar}^{\mathrm{f} / \mathrm{fl}} \mathrm{Cd} 19-\mathrm{Cre}^{\mathrm{ki} / \mathrm{ki}}$ genotype is linked to an almost complete penetrance of Adar ablation in late B cell precursors of these mutant mice.

\section{ADAR1 is required for IL-7-dependent in vitro generation of late $B$ cell precursors}

To validate that the significant defect in late B cell precursor maturation in our model is mainly ADAR1dependent, we cultured BM cells from $\mathrm{Adar}^{\mathrm{f} / \mathrm{fl}} \mathrm{Cd} 19-\mathrm{Cre}^{\mathrm{ki} /+}$ mutants (Cd19 sufficient) with IL-7 for 5 and 7 days. This in vitro culture system permitted us to study the expansion and maturation of IL7R ${ }^{+} \mathrm{CD} 19^{-} \mathrm{B}-$-lineage early precursors into $\mathrm{B} 220^{+} \mathrm{CD} 19^{+}$late precursors (Fr. D/E). As predicted, we found that the in vitro generation of $\mathrm{CD} 19^{+} \mathrm{B}$ cell precursors was significantly reduced $(p<0.0001)$ at both time points in $\mathrm{Adar}^{\mathrm{f} / \mathrm{f}} \mathrm{Cd} 19-\mathrm{Cre}^{\mathrm{k} / /+}$ mutants compared to control Adar ${ }^{\mathrm{f} / /+} \mathrm{Cd} 19-\mathrm{Cre}^{\mathrm{ki} /+}$ littermate cultures (Figure 3A). In contrast, in vitro generation of late $\mathrm{B}$ cell precursors was largely normal in $\mathrm{Adar}^{\mathrm{fl} /+} \mathrm{Cre}^{\mathrm{ki} / \mathrm{ki}} \mathrm{BM}$ cultures.

Additionally, to confirm ongoing Cd19-Cremediated Adar gene segment excision in our model, we analyzed the genomic DNA purified from day 5 cultures, by gel electrophoresis for the following PCR products: Adar $\Delta$ allele alone (lane 1), wt \& fl alleles (lane 2), or all the three alleles simultaneously (lane 3 ). We found that loxP site recombination was prominent in vitro in the three mice genotypes (Figure 3B, lane \#1 in all samples). Moreover, the densitometry of band intensities of the $\operatorname{Adar}^{\mathrm{f} / \mathrm{fl}} \mathrm{Cd} 19-\mathrm{Cre}^{\mathrm{ki} /+}$ sample (lane \#3), revealed that the relative level of $\Delta$ allele was 0.54 -fold compared to the $f$ allele (Figure 3B, see bar graph). This important finding demonstrates, as previously reported $[10,30]$, that incomplete penetrance of Cre-mediated Adar recombination results in selection against cells with biallelic Adar ablation. Moreover, $\operatorname{Adar}^{\mathrm{f} / /+} \mathrm{Cd} 19-$ $\mathrm{Cre}^{\mathrm{ki} / \mathrm{ki}} \mathrm{BM}$ cultures displayed the highest efficiency of Adar recombination: the relative level of the $\Delta$ allele (normalized to $f$ allele) was 1.51 -fold compared to 0.68 and 0.54 -fold in the other two littermate groups (Figure
3B, bar graph). Taken together these data confirm that Cd19-Cre ${ }^{\mathrm{ki}}$ homozygosity is coupled with a several-fold higher efficiency of floxed gene segment recombination, supporting the conclusion that the substantial block in B lymphopoiesis in $\mathrm{Adar}^{\mathrm{f} / \mathrm{f}} \mathrm{Cd} 19-\mathrm{Cre}^{\mathrm{ki} / \mathrm{ki}}$ mice is mainly due to an almost complete penetrance of Adar ablation and its detrimental biological consequences.

\section{Adar ablation in B cell precursors leads to apoptosis and upregulation of typical ISGs}

By Annexin-V staining of BM cells cultured overnight (Figure 4A), we found an increased rate of apoptosis of immature B cells from $\mathrm{Adar}^{\mathrm{f} / \mathrm{fl}} \mathrm{Cd19}$ $\mathrm{Cre}^{\mathrm{ki} / \mathrm{ki}}$ and $\mathrm{Adar}^{\mathrm{f} / \mathrm{fl}} \mathrm{Cd} 19-\mathrm{Cre}^{\mathrm{ki} /+}$ mutants compared to relevant littermate controls $(\sim 12$ - and $\sim 4$-fold increase, respectively). Our data agree with previous data showing that the loss of ADAR1 in Hematopoietic stem cells leads to rapid apoptosis [10]. The two major pathways previously linked to the induction of apoptosis in ADAR1 deficient cells include: (i) excessive activation of the dsRNA-dependent eukaryotic translation initiation factor 2-alpha kinase (Eif2ak2/PKR) with subsequent inhibition of protein synthesis; and (ii) dsRNA-dependent RIG-I-like receptors (RLR) mediated activation of IRF3 and a robust type-I interferons response [31, 32].

Next, to study whether Adar ablation in B cell precursors was linked to aberrant induction of the PKR and RLR dependent signaling pathways, we first isolated by FACSorting pro-B and pre-B cells from the BMs of $\mathrm{Adar}^{\mathrm{f} / \mathrm{fl}} \mathrm{Cd} 19-\mathrm{Cre}^{\mathrm{ki} / \mathrm{ki}}$ mice and littermate controls. Total RNA from the FACS-sorted cells was then analyzed by qRTPCR for the relative quantity of a group of selected ISGs downstream of RLR activation (IRF7, CXCL10, RSAD2, and IFIT1). In pro-B cells, we found increased levels of IRF3 and PKR, both linked to the activation of pro-apoptotic pathways following ADAR1 silencing [33, 34]. In pre-B cells, we found increased transcription of all four selected ISGs (Figure 4B). Interestingly, IRF7 that was strongly upregulated in ADAR1 deficient pre-B cells is a major enhancer of the RLR mediated innate immune response $[35,36]$; thus implying robust activation of this response in our model. Since the percentage of late B cell precursors (Fr. E/F) was extremely low in the BM of mutant mice, with the majority of these rare cells rapidly undergoing to apoptosis, we could not study the effect of Adar ablation directly in this relevantcell population.

Nucleic acids are the essential carriers of genetic information for all living organisms. Thus, selective identification of foreign nucleic acids is a major undertaking of the mammalian innate immune system [36]. Recent advances imply a role for dysregulation of nucleic acid sensing pathways in human autoimmunity $[3,13,19]$. In fact, mutations in ADAR1 are a genetic cause of the prototypic interferonopathy, AGS, displaying 

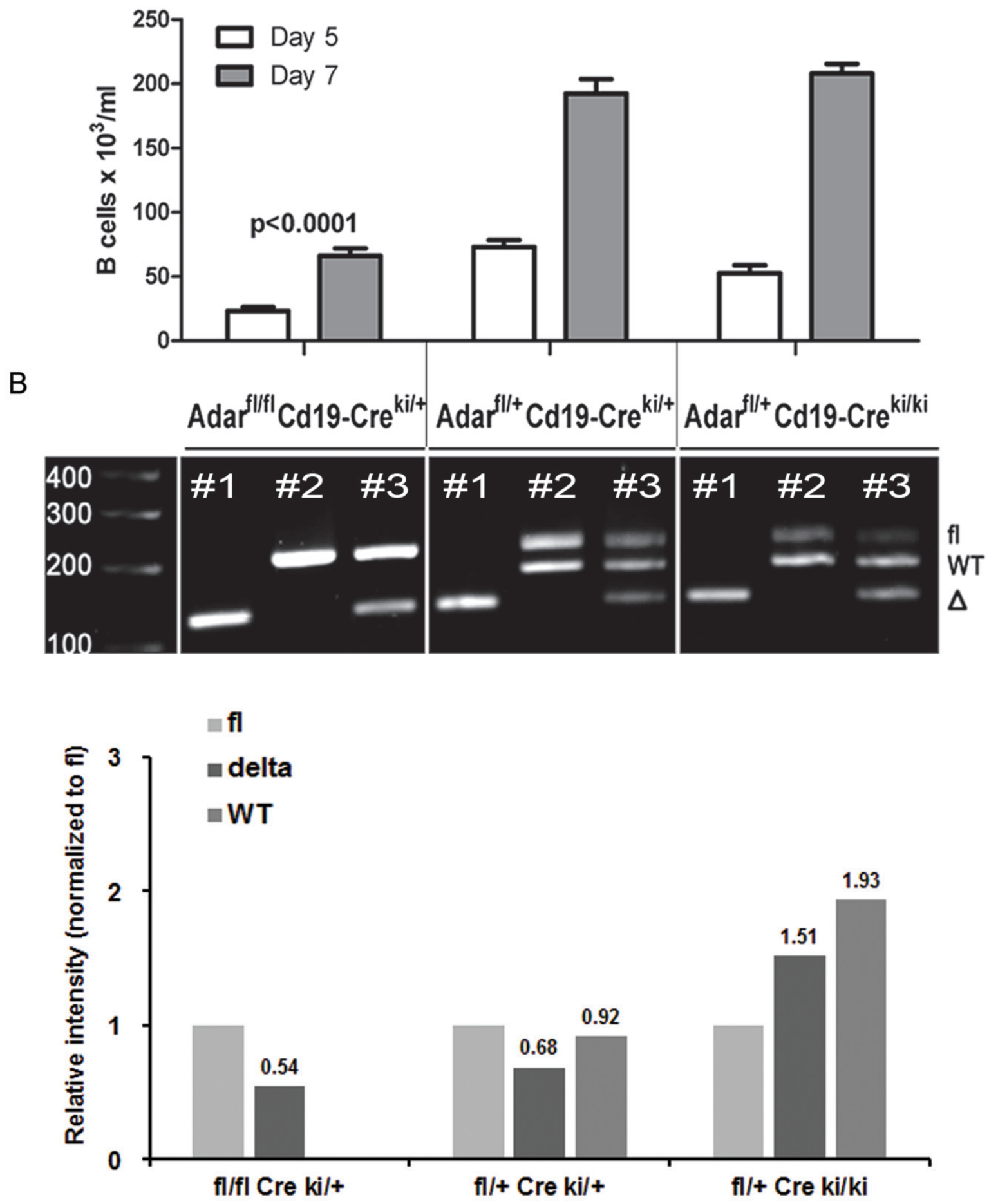

Figure 3: B cell precursors from Adar $^{\mathrm{n} / / \mathrm{l}} \mathrm{Cd19-Cre}{ }^{\mathrm{k} /+}$ display a significantly reduced capacity for IL-7-dependent generation of $\mathrm{CD}^{+}{ }^{+} \mathrm{B}$ cells in vitro. A. Bone marrow cells supplemented with rhIL-7 were cultured for 5 or 7 days, as described in methods. Cells were harvested, at the indicated time points, and absolute number of $\mathrm{CD} 19^{+} \mathrm{B}$ cells per $\mathrm{mL}$ was determined by FACS with the 123 count eBeads kit. BM cultures were done in triplicates and bar graphs depict mean $( \pm \mathrm{SD})$ from a representative experiment out of $>$ 3 performed. Absolute $\mathrm{CD} 19^{+} \mathrm{B}$ cell counts in BM cultures of Adar ${ }^{\mathrm{f} / \mathrm{f}} \mathrm{Cd} 19-\mathrm{Cre}^{\mathrm{k} /+}$ mutants were significantly lower $(p<0.0001$ by one-way ANOVA test) compared to the other groups at both time points. B. At the end of BM cultures (day 7), purified DNA from each respective sample was analyzed by PCR to detect relative quantity of either the Adar $\Delta$ allele (lane 1), wt \& fl alleles (lane 2), or all the three alleles simultaneously (lane 3). The image was acquired using a Molecular Imager ChemiDoc XRS ${ }^{+}$system, and the densitometry analysis of the bands intensity was done using the Image Lab 5.1 software (BioRad Laboratories, Inc.). 
similarities with familial SLE including the production of distinct autoantibodies to nuclear proteins [14, 15]. Moreover, recent studies in mouse models show that genetic deletion of Mavs can rescue Adar ${ }^{/-}$mice to birth. Likewise, Adar ${ }^{\mathrm{E} 861 \mathrm{~A} / \mathrm{E} 861 \mathrm{~A}}$ knock in mice, expressing only a catalytically inactive ADAR1 and displaying embryonic lethality, could be rescued by concurrent knocking-out of Ifih1, encoding the cytoplasmic dsRNA sensor MDA5 $[8,9]$. Activation of MDA5 induces the polymerization of MAVS that recruits and activates selected TRAF E3-ligases. This mediates the activation of the IKK and TBK1 kinases to phosphorylate $\mathrm{I} \kappa \mathrm{B} \alpha$ and IRF3, respectively, leading to the robust transcription of ISGs and other cytokines [36, 37]. Taken as a whole these observations imply that a major biological function of
ADAR1, conserved across mammalians, is the editing of repetitive sequences in transcripts that prevent the abnormal activation of MDA5 by self-dsRNAs. Indeed, our observation that a group of typical ISGs was upregulated in pre-B cells of $\mathrm{Adar}^{\mathrm{f} / \mathrm{fl}} \mathrm{Cd} 19-\mathrm{Cre}^{\mathrm{k} / \mathrm{ki}}$ mutant mice is consistent with the latter paradigm.

A previous report from the Nishikura laboratory [38] describes the use of Cd19-Cre mediated ablation of Adar to study its role in the biogenesis of miR-142 by splenic $\mathrm{B}$ cells. However, this report did not provide pertinent data regarding the effects of ADAR1 deficiency on B cell development and survival in the BM or spleen, and hence its relevance to our study is small. Pestal et al. have very recently reported that Adar and Mavs double knockout mice, surviving past 1 week of age, show a significant

\section{A}

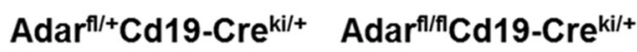

Adar $^{\mathrm{f} /+} \mathrm{Cd} 19-\mathrm{Cre}^{\mathrm{ki} / \mathrm{ki}}$

Adar ${ }^{\mathrm{f} / \mathrm{f}} \mathrm{Cd19}-\mathrm{Cre} \mathrm{ki}^{\mathrm{k} / \mathrm{ki}}$
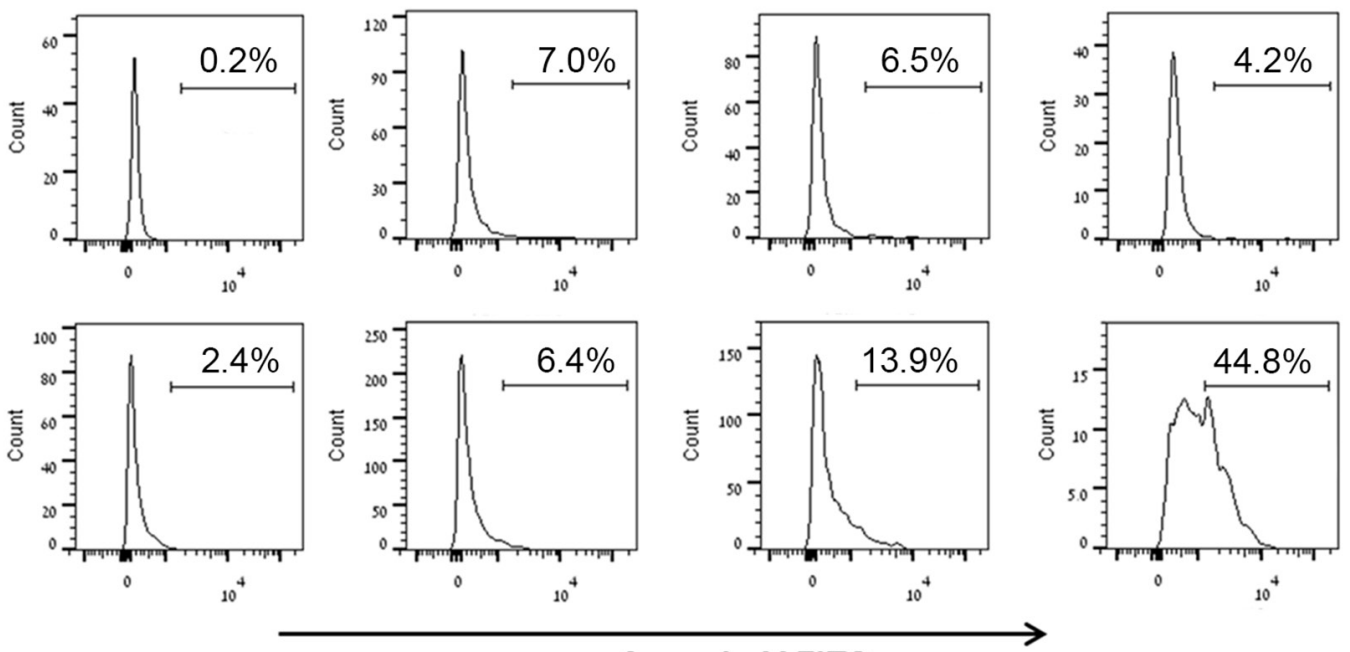

Annexin V-FITC

B
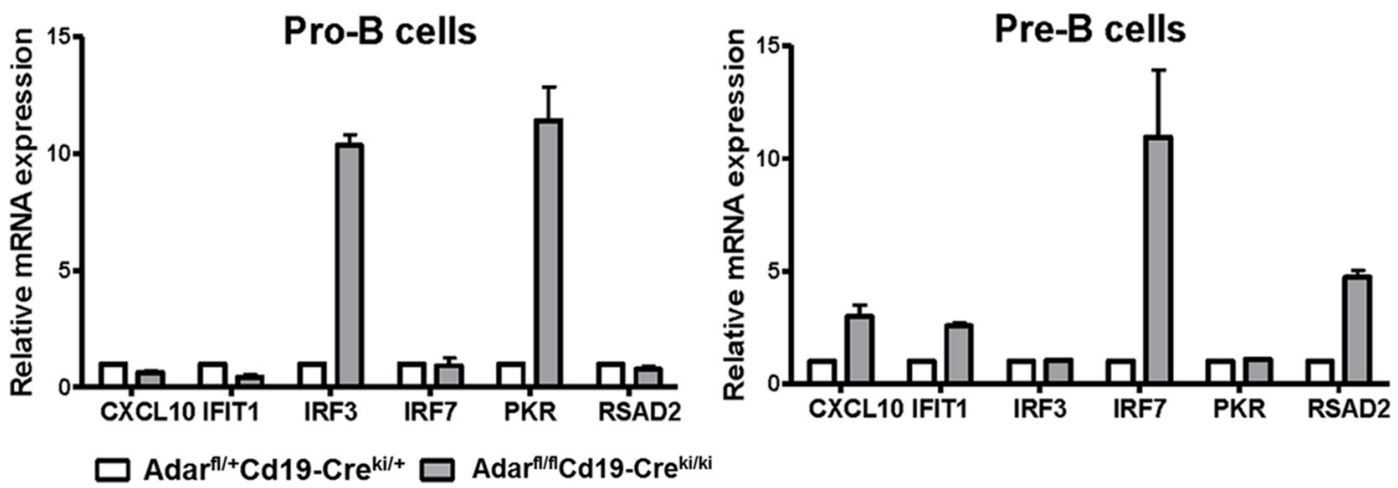

Figure 4: Cd19-Cre dependent disruption of Adar leads to apoptosis and type-I interferons response. A. Histograms depict FACS analysis of Annexin V staining of pre-B cells (upper panel) and immature B cells (lower panel) following overnight in vitro incubation. C. Pro-B cells and pre-B cells were isolated from BMs by a FACSAria sorter, and total RNA was purified from the cells as detailed in Methods. Next, we measured by qRTPCR the relative mRNA expression of the indicated ISGs. Bar graphs depict mean of triplicates $( \pm \mathrm{SD})$, as calculated by the $\Delta \Delta \mathrm{CT}$ method, normalized to Gapdh gene expression. Data show a representative experiment out of three performed. 
deficiency of mature peripheral B cells, but not of T cells and dendritic cells, within their peripheral lymphoid organs [17]. Unlike our work, the authors did not study the effect of germline Adar deletion on the process of B lymphopoiesis in the BM nor whether ADAR1 was vital, in this model, for the early (Fr. A/B), late (Fr. C-E) and/or final (Fr. F) B development. Importantly, our novel finding that ISGs are significantly upregulated in ADAR1 lacking pre-B cells is consistent with their observation, employing the Adar ${ }^{\text {p150-/- }}$ mouse model [39], that the B cell deficiency is ADAR1 p150 isoform dependent [17]. This interferoninducible isoform, as opposed to the constitutive p110 isoform, performs its catalytic function mainly in the cytosol, playing a key role in the cytosolic regulatory network enabling tolerance to paired RNA components (dsRNAs) of the trascriptome [3, 19, 20].

Pertinently, we have just revealed that hepatocytespecific ablation of ADAR1 induces massive liver damage with multifocal inflammation and hepatocyte apoptosis. The bioinformatics analysis of the whole transcript expression arrays from these abnormal livers indicated a robust upregulation of ISGs and related immune response genes [30]. Thus, we now communicate multiple data that Adar, is not only vital for stem/progenitor type cells in the fetal and early postnatal period, but also for more differentiated functional cells in adult mice: e.g., hepatocytes and newly formed immature B cells with functional surface $\operatorname{IgM}$ receptor.

In conclusion, we show for the first time that ADAR1, the master transcriptome editor, is essential for the late stages of B cell lymphoiesis in the BM and very likely for the survival of newly formed B cells in the periphery. Since the perturbation of nucleic acid sensing pathways and of autoreactive B cells plays a central role in SLE $[40,41]$ our data imply that further insight into the immunoregulatory role of ADAR1 may be relevant for a subset of autoimmune disorders.

\section{MATERIALS AND METHODS}

\section{In vivo $\mathrm{B}$ cell-specific Cd19-Cre mediated conditional disruption of Adar}

Mice with a loxP-flanked Adar ${ }^{\mathrm{f7}-9}\left(\operatorname{Adar}^{\mathrm{fl}}\right)$ allele through the germline were previously described [11]. Homozygous Adar ${ }^{\mathrm{f} / \mathrm{fl}}$ mice backcrossed into the C57BL/6 background were kindly provided by Stuart H. Orkin (Dana-Farber Cancer Institute, Boston, MA) and Peter H. Seeburg (Max Planck Institute for Medical Research, Heidelberg, Germany). The B6.129P2(C)-Cd19 ${ }^{\mathrm{tm} 1(\mathrm{cre}) \mathrm{Cgn} / \mathrm{J}}$ deleter mice were obtained from The Jackson Laboratory (Bar Harbor, ME). The Cd19-Cre knock-in/knock-out allele (Cd19-Cre ${ }^{\mathrm{ki}}$ ) has a Cre gene inserted into the first exon of the Cd19 gene [27].
To generate mice with $\mathrm{B}$ cell lineage-specific disruption of Adar we first bred Adar ${ }^{\mathrm{f} / \mathrm{fl}}$ mice to $\mathrm{Cd} 19-\mathrm{Cre}^{\mathrm{ki} /}$ ${ }^{\mathrm{ki}}$ deleter mice to produce $\mathrm{Adar}^{\mathrm{f} / /+} \mathrm{Cd} 19-\mathrm{Cre}^{\mathrm{ki} /+}$ offspring that were further interbred to generate four different genotypes. Two relevant mutant genotypes $\left(\operatorname{Adar}^{\mathrm{f} / \mathrm{f}} \mathrm{Cd} 19^{\mathrm{ki} /}\right.$ ki / Adar $\left.{ }^{\mathrm{f} / \mathrm{fl}} \mathrm{Cd} 19-\mathrm{Cre}^{\mathrm{ki} /+}\right)$ with high and low efficiency of biallelic B cell-specific Adar ${ }^{4-9}$ somatic gene segment excision, respectively, and two relevant littermate controls $\left(\right.$ Adar $^{\mathrm{f} /+} \mathrm{Cd} 19-\mathrm{Cre}^{\mathrm{ki} / \mathrm{ki}} / \mathrm{Adar}^{\mathrm{f} / /+} \mathrm{Cd} 19-\mathrm{Cre}^{\mathrm{ki} /+}$ ). Genomic DNA samples isolated from the tail tips of $3 \mathrm{wk}$ mice pups were analyzed by multiplex PCR that simultaneously detects Adar the $\operatorname{wt}^{+}()$, floxed $\left({ }^{\mathrm{fl}}\right)$, and excised $\left({ }^{\Delta 7-9}\right)$ alleles, as previously described [11]. In paralleled, the presence of the Cd19-Cre ${ }^{\mathrm{ki}}$ and/or the wt $\left(^{+}\right)$allele was determined by a different multiplex PCR assay [27]. Additionally, to verify actual Cd19-Cre ${ }^{\mathrm{ki}}$-dependent Adar gene disruption, selected DNA samples from BM cells of 8-16 week old mutant and littermate control mice were analyzed by multiplex PCR for the presence of $\mathrm{Adar}^{+}$, fl, or excised ${ }^{\Delta 7-9}$ alleles. The mice were bred and housed in a SPF facility, and did not display any gross abnormalities as mature adults (3-6 months of age). The Institutional Animal Care and Use Committee of the Weizmann Institute of Science (Rehovot, Israel) approved all animal experiments.

\section{FACS analysis of B cell developmental stages}

Single-cell suspensions of BM, Spleen, and of blood cells were obtained from 8-16 week old mice. Depletion of erythrocytes from the various sample was achieved using Red Blood Cell Lysis Buffer (Sigma-Aldrich Chemie $\mathrm{GmbH}$, Steinheim, Germany). Next, the cells were immunostained with a relevant mixture of flourochrome conjugated mAbs against any of the following selected mouse B cell surface antigens B220/CD45R, CD19, CD43, HSA/CD24, CD25, AA4.1/CD93, CD23, IgM, and IgD; all obtained from eBioscience Inc. (San Diego, CA). Next, by polychromatic flow cytometry we analyzed the samples for relevant B cell developmental stages in the $\mathrm{BM}$ and periphery according to the Hardy classification and the Philadelphia nomenclature [26, 42]. The following $\mathrm{B}$ cells stages were identified: pro-B/Fr. B-C (B220 $\mathrm{CD}^{-} \mathrm{CD}^{-} 3^{+} \mathrm{CD}^{2} 4^{++} \mathrm{CD} 9^{+/++} \mathrm{CD}^{+} 3^{+}$); pre-B/Fr. D $\left(\mathrm{B} 220^{++} \mathrm{CD}^{25^{+}} \mathrm{CD}^{-} 3^{-} \mathrm{CD} 24^{++} \mathrm{CD} 9^{++} \mathrm{CD}^{++} \mathrm{IgM}^{-}\right)$; immature/Fr. E (B220 ${ }^{+++}$CD43+ CD24 ${ }^{\text {hi }} \mathrm{CD} 19^{+++} \mathrm{CD}^{++}$ $\left.\mathrm{CD}^{2} 5^{-} / \mathrm{IgM}^{+} \mathrm{IgD}^{-}\right)$; mature recirculating/Fr. F (B220 ${ }^{+++}$ $\left.\mathrm{CD} 9^{+++} \mathrm{CD} 23^{++/ h i} \mathrm{CD}^{-}\right)$; and splenic transitional T2 plus follicular $\left(\mathrm{B} 220^{+++} \mathrm{CD} 19^{+++} \mathrm{CD} 23^{++/ \text {hi }}\right)$. Data were acquired on a FACSAria instrument (BD Biosciences, San Jose, CA), and analyzed/plotted using the FlowJo V.10 software (FlowJo, Ashland, OR). 


\section{Isolation of pro- and pre-B cells from BM}

Single-cell suspensions of BM derived cells from 8-16 week old mutant and littermate controls were depleted of red blood cells and immunostained for relevant cell surface markers, as detailed above. Subsequently, we sorted out pro-B cells and pre B-cells using a FACSAria instrument to high purity ( $\sim 95 \%)$, as previously described [43]. Next, the purified cell were lysed with TRIzol ${ }^{\circledR}$ Reagent (Invitrogen, Carlsbad, CA) and total RNA was purified using Direct-zol ${ }^{\mathrm{TM}}$ RNA Kits (Zymo Research Corporation, Irvine, CA) for subsequent downstream analysis. The quantification of selected gene transcripts was performed by quantitative PCR (qRTPCR) using specific predesigned pair of unlabeled PCR primers and a TaqMan ${ }^{\circledR}$ probe $\left(\right.$ TaqMan $^{\circledR}$ Gene Expression Assays) and analyzed on an ABI PRISM 7300 Sequence Detection system (all reagents and the analyzer were from Applied Biosystems, Thermo Fisher Scientific Inc.). Selected DNA samples from pre-B cells of Adar ${ }^{\mathrm{f} / \mathrm{f}} \mathrm{Cd} 19-\mathrm{Cre}^{\mathrm{k} i k \mathrm{ki}}$ mutants and controls were also analyzed by multiplex PCR to verify enrichment for the Adar ${ }^{\Delta 7-9}$ allele in the mutant mice samples.

\section{BM cell cultures}

To induce the IL7-dependent in vitro expansion and differentiation of early IL $7 \mathrm{R}^{+}$lymphoid progenitors, $\mathrm{BM}$ cultures were prepared as previously described [43]. Briefly, single cell suspension of BM cells obtained from the femurs of 8-16 week-old mice were first depleted of erythrocytes using Red Blood Cell Lysis Buffer (SigmaAldrich Chemie $\mathrm{GmbH}$ ), per manufacturer's instructions. Then, BM cells were cultured, at $5 \times 10^{5}$ cells $/ \mathrm{ml}$ in a 6-well plate, for 5 and 7 days in Iscove modified Dulbecco medium supplemented with $100 \mathrm{IU} / \mathrm{mL}$ of recombinant human IL-7 (PeproTech, Rocky Hill, NJ). At the end of the experiment, we performed absolute counting of B220 $\mathrm{CD} 19^{+}$cells by flow cytometry employing the 123 count eBeads kit (eBioscience Inc.), according to manufacturer's instructions. As expected, usually at the end of culturing most of the cells were in vitro formed $\mathrm{B} 220^{\mathrm{int}} \mathrm{CD} 19^{+} \mathrm{B}$ cell precursors.

\section{Statistical analysis}

Statistically significant differences between group means were determined by one-way ANOVA test with Dunnett's post hoc multiple comparison method, using Prism win V.5.02 (GraphPad Software, Inc. La Jolla, CA).

\section{ACKNOWLEDGMENTS}

The authors thank Shirley Oren Ben-Shoshan for technical assistance.

G.R. is the incumbent of the Djerassi Chair in Oncology at the Sackler School of Medicine, Tel-Aviv University, Tel-Aviv 6997801, Israel.

\section{CONFLICTS OF INTEREST}

The authors declare no conflict of interest.

\section{GRANT SUPPORT}

This study was supported by The Varda and Boaz Dotan Research Center in Hemato-oncology affiliated with the CBRC of Tel Aviv University (I.G. and G.R.); The Israeli Centers for Research Excellence I-CORE Program (ISF grants no. 41/11 and no. 1796/12 to G.R.); and The Flight Attendant Medical Research Institute (G.R.).

\section{Editorial note}

This paper has been accepted based in part on peerreview conducted by another journal and the authors' response and revisions as well as expedited peer-review in Oncotarget.

\section{REFERENCES}

1. Levanon EY, Eisenberg E, Yelin R, Nemzer S, Hallegger M, Shemesh R, Fligelman ZY, Shoshan A, Pollock SR, Sztybel D, Olshansky M, Rechavi G and Jantsch MF. Systematic identification of abundant A-to-I editing sites in the human transcriptome. Nat Biotechnol. 2004; 22: 10011005.

2. Dominissini D, Moshitch-Moshkovitz S, Schwartz S, Salmon-Divon M, Ungar L, Osenberg S, Cesarkas K, JacobHirsch J, Amariglio N, Kupiec M, Sorek R and Rechavi G. Topology of the human and mouse m6A RNA methylomes revealed by m6A-seq. Nature. 2012; 485: 201-206.

3. O'Connell MA, Mannion NM and Keegan LP. The Epitranscriptome and Innate Immunity. PLoS Genet. 2015; 11: e1005687.

4. George CX, Wagner MV and Samuel CE. Expression of interferon-inducible RNA adenosine deaminase ADAR1 during pathogen infection and mouse embryo development involves tissue-selective promoter utilization and alternative splicing. J Biol Chem. 2005; 280: 15020-15028.

5. Eisenberg E, Adamsky K, Cohen L, Amariglio N, Hirshberg A, Rechavi $G$ and Levanon EY. Identification of RNA editing sites in the SNP database. Nucleic Acids Res. 2005; 33: 4612-4617.

6. Neeman Y, Levanon EY, Jantsch MF and Eisenberg E. RNA editing level in the mouse is determined by the genomic repeat repertoire. RNA. 2006; 12: 1802-1809.

7. Porath HT, Carmi S and Levanon EY. A genome-wide 
map of hyper-edited RNA reveals numerous new sites. Nat Commun. 2014; 5.

8. Liddicoat BJ, Piskol R, Chalk AM, Ramaswami G, Higuchi M, Hartner JC, Li JB, Seeburg PH and Walkley CR. RNA editing by ADAR1 prevents MDA5 sensing of endogenous dsRNA as nonself. Science. 2015; 349: 1115-1120.

9. Mannion NM, Greenwood SM, Young R, Cox S, Brindle J, Read D, Nellaker C, Vesely C, Ponting CP, McLaughlin PJ, Jantsch MF, Dorin J, Adams IR, Scadden AD, Ohman M, Keegan LP, et al. The RNA-editing enzyme ADAR1 controls innate immune responses to RNA. Cell Rep. 2014; 9: 1482-1494.

10. Hartner JC, Walkley CR, Lu J and Orkin SH. ADAR1 is essential for the maintenance of hematopoiesis and suppression of interferon signaling. Nat Immunol. 2009; 10: 109-115.

11. Hartner JC, Schmittwolf C, Kispert A, Müller AM, Higuchi $\mathrm{M}$ and Seeburg PH. Liver Disintegration in the Mouse Embryo Caused by Deficiency in the RNA-editing Enzyme ADAR1. Journal of Biological Chemistry. 2004; 279: 48944902.

12. Wang Q, Khillan J, Gadue P and Nishikura K. Requirement of the RNA editing deaminase ADAR1 gene for embryonic erythropoiesis. Science. 2000; 290: 1765-1768.

13. Crow YJ and Manel N. Aicardi-Goutieres syndrome and the type I interferonopathies. Nat Rev Immunol. 2015; 15: 429-440.

14. Rice GI, Kasher PR, Forte GM, Mannion NM, Greenwood SM, Szynkiewicz M, Dickerson JE, Bhaskar SS, Zampini M, Briggs TA, Jenkinson EM, Bacino CA, Battini R, Bertini E, Brogan PA, Brueton LA, et al. Mutations in ADAR1 cause Aicardi-Goutieres syndrome associated with a type I interferon signature. Nat Genet. 2012; 44: 12431248 .

15. Rice G, Patrick T, Parmar R, Taylor CF, Aeby A, Aicardi J, Artuch R, Montalto SA, Bacino CA, Barroso B, Baxter P, Benko WS, Bergmann C, Bertini E, Biancheri R, Blair EM, et al. Clinical and Molecular Phenotype of AicardiGoutières Syndrome. The American Journal of Human Genetics. 2007; 81: 713-725.

16. Goutieres F. Aicardi-Goutieres syndrome. Brain Dev. 2005; 27: 201-206.

17. Pestal K, Funk CC, Snyder JM, Price ND, Treuting PM and Stetson DB. Isoforms of RNA-Editing Enzyme ADAR1 Independently Control Nucleic Acid Sensor MDA5-Driven Autoimmunity and Multi-organ Development. Immunity. 2015; 43: 933-944.

18. Funabiki M, Kato H, Miyachi Y, Toki H, Motegi H, Inoue $\mathrm{M}$, Minowa $\mathrm{O}$, Yoshida $\mathrm{A}$, Deguchi $\mathrm{K}$, Sato $\mathrm{H}$, Ito S, Shiroishi T, Takeyasu K, Noda T and Fujita T. Autoimmune Disorders Associated with Gain of Function of the Intracellular Sensor MDA5. Immunity. 2014; 40: 199-212.

19. Liddicoat BJ, Chalk AM and Walkley CR. ADAR1, inosine and the immune sensing system: distinguishing self from non-self. Wiley Interdisciplinary Reviews: RNA. 2016; 7: 157-172.

20. Mannion N, Arieti F, Gallo A, Keegan LP and O'Connell MA. New Insights into the Biological Role of Mammalian ADARs; the RNA Editing Proteins. Biomolecules. 2015; 5: 2338-2362.

21. Bass BL. RNA editing by adenosine deaminases that act on RNA. Annu Rev Biochem. 2002; 71:817-846.

22. Solomon O, Oren S, Safran M, Deshet-Unger N, Akiva P, Jacob-Hirsch J, Cesarkas K, Kabesa R, Amariglio N, Unger $\mathrm{R}$, Rechavi G and Eyal E. Global regulation of alternative splicing by adenosine deaminase acting on RNA (ADAR). RNA. 2013; 19: 591-604.

23. Nishikura K. Functions and Regulation of RNA Editing by ADAR Deaminases. Annu Rev Biochem. 2009; 79:321349.

24. Ota H, Sakurai M, Gupta R, Valente L, Wulff BE, Ariyoshi $\mathrm{K}$, Iizasa H, Davuluri RV and Nishikura K. ADAR1 forms a complex with Dicer to promote microRNA processing and RNA-induced gene silencing. Cell. 2013; 153: 575-589.

25. XuFeng R, Boyer MJ, Shen H, Li Y, Yu H, Gao Y, Yang Q, Wang Q and Cheng T. ADAR1 is required for hematopoietic progenitor cell survival via RNA editing. Proc Natl Acad Sci U S A. 2009; 106: 17763-17768.

26. Hardy RR and Hayakawa K. B cell development pathways. Annu Rev Immunol. 2001; 19:595-621.

27. Rickert RC, Rajewsky K and Roes J. Impairment of T-celldependent B-cell responses and B-1 cell development in CD19-deficient mice. Nature. 1995; 376: 352-355.

28. Rickert RC, Roes J and Rajewsky K. B lymphocytespecific, Cre-mediated mutagenesis in mice. Nucleic Acids Res. 1997; 25: 1317-1318.

29. Wang Y, Brooks SR, Li X, Anzelon AN, Rickert RC and Carter RH. The Physiologic Role of CD19 Cytoplasmic Tyrosines. Immunity. 2002; 17: 501-514.

30. Ben-Shoshan SO, Kagan P, Sultan M, Barabash Z, Dor C, Jacob-Hirsch J, Harmelin A, Pappo O, Marcu-Malina V, Ben-Ari Z, Amariglio N, Rechavi G, Goldstein I and Safran M. ADAR1 deletion induces NFkappaB and interferon signaling dependent liver inflammation and fibrosis. RNA Biol. 2016; doi: 10.1080/15476286.2016.1203501.

31. McAllister CS and Samuel CE. The RNA-activated protein kinase enhances the induction of interferon-beta and apoptosis mediated by cytoplasmic RNA sensors. J Biol Chem. 2009; 284: 1644-1651.

32. Vitali P and Scadden ADJ. dsRNAs containing multiple IU pairs are sufficient to suppress interferon induction and apoptosis. Nature structural \& molecular biology. 2010; 17: 1043-1050.

33. Toth AM, Li Z, Cattaneo R and Samuel CE. RNA-specific adenosine deaminase ADAR1 suppresses measles virusinduced apoptosis and activation of protein kinase PKR. J Biol Chem. 2009; 284: 29350-29356. 
34. Pfaller CK, Li Z, George CX and Samuel CE. Protein kinase PKR and RNA adenosine deaminase ADAR1: new roles for old players as modulators of the interferon response. Curr Opin Immunol. 2011; 23: 573-582.

35. Honda K, Yanai H, Negishi H, Asagiri M, Sato M, Mizutani T, Shimada N, Ohba Y, Takaoka A, Yoshida N and Taniguchi T. IRF-7 is the master regulator of type-I interferon-dependent immune responses. Nature. 2005; 434: 772-777.

36. $\mathrm{Wu} \mathrm{J}$ and $\mathrm{Chen} \mathrm{ZJ}$. Innate immune sensing and signaling of cytosolic nucleic acids. Annu Rev Immunol. 2014; 32:461488.

37. Seth RB, Sun L, Ea C-K and Chen ZJ. Identification and Characterization of MAVS, a Mitochondrial Antiviral Signaling Protein that Activates NF-B and IRF3. Cell. 2005; 122: 669-682.

38. Yang W, Chendrimada TP, Wang Q, Higuchi M, Seeburg $\mathrm{PH}$, Shiekhattar R and Nishikura K. Modulation of microRNA processing and expression through RNA editing by ADAR deaminases. Nat Struct Mol Biol. 2006; 13: 1321.

39. Ward SV, George CX, Welch MJ, Liou L-Y, Hahm B, Lewicki H, de la Torre JC, Samuel CE and Oldstone MB. RNA editing enzyme adenosine deaminase is a restriction factor for controlling measles virus replication that also is required for embryogenesis. Proceedings of the National Academy of Sciences of the United States of America. 2011; 108: 331-336.
40. Banchereau J and Pascual V. Type I Interferon in Systemic Lupus Erythematosus and Other Autoimmune Diseases. Immunity. 2006; 25: 383-392.

41. Kirou KA, Lee C, George S, Louca K, Peterson MGE and Crow MK. Activation of the interferon- pathway identifies a subgroup of systemic lupus erythematosus patients with distinct serologic features and active disease. Arthritis \& Rheumatism. 2005; 52: 1491-1503.

42. Osmond DG, Rolink A and Melchers F. Murine B lymphopoiesis: towards a unified model. Immunol Today. 1998; 19: 65-68.

43. Oliver PM, Wang M, Zhu Y, White J, Kappler J and Marrack P. Loss of Bim Allows Precursor B Cell Survival But Not Precursor B Cell Differentiation in the Absence of Interleukin 7. The Journal of Experimental Medicine. 2004; 200: 1179-1187. 